\title{
Practice Corner: Taking evidence in hand
}

Come with us while our clinical team makes rounds. As each patient is seen and discussed, we often find that we have gaps in our knowledge related to the clinical decisions we're making. In this Practice Corner, we'll illustrate how we meet some of those information needs rapidly using resources stored in a personal digital assistant (PDA), ${ }^{1}$ placing in brackets the time it takes us to retrieve the evidence. We'll provide contact information in a table for selected resources and more information is available on our website (www:wsuim.org/PDA). Wherever possible, we use PDA resources that are evidence-based, meaning that their manufacturers are fully explicit about how they searched for evidence on clinical questions, appraised that evidence critically and rated its strength, and tied the strength of the evidence to the recommendations made. ${ }^{2}$

Our first patient is an older man admitted for pneumonia, in whom the medical student found a surprising abdominal pulsation. On examination we confirm that the aortic pulse contour is $3 \mathrm{~cm}$ wide. How accurate is this finding for detecting abdominal aortic aneurysm? On our Palm OS-based PDA, we tap the "Find" function, enter "AAA", and then tap open a memo that tells us that the positive likelihood ratio of this clinical finding for abdominal aortic aneurysm is 12.0 [4 seconds]. In this memo we'd written a synopsis of the evidence, similar in structure to the larger Critically Appraised Topic $(\mathrm{CAT})^{2}$ but in a PDAfriendly format we call an eCAT (table 1). Using the infrared port, we can share this memo with team members who have Palm OS-based PDAs.

An older woman has anaemia. We suspect the cause is renal failure, but we want to exclude iron deficiency. Her serum ferritin value is $126 \mathrm{ng} / \mathrm{ml}$, raising the question of whether this "negative" result is sufficiently powerful to rule out iron deficiency. We tap to another eCAT (table 1) from which we learn that the likelihood ratio of this ferritin result is 0.08 , small enough that the post-test probability for our patient is now below our test threshold [4 seconds].

When we summarise our evidence-based learning activities in the form of eCATs, we can be sure of our own methods for acquiring, appraising, and applying the evidence. Yet since our information needs are much greater than the time available to appraise evidence and

Table 1. eCATs: Elements and examples

\begin{tabular}{|c|c|c|c|c|c|}
\hline Element & \multicolumn{3}{|l|}{ Example 1} & \multicolumn{2}{|l|}{ Example 2} \\
\hline Short title & \multicolumn{3}{|c|}{ Palpation for abdominal aortic aneurysm (AAA) } & \multicolumn{2}{|l|}{ Ferritin for iron deficiency } \\
\hline Bottom line & \multicolumn{3}{|c|}{$\begin{array}{l}\text { 1. Abnormal aortic contour on palpation can raise probability of AAA greatly. } \\
\text { 2. Normal palpation cannot accurately rule out AAA. }\end{array}$} & \multicolumn{2}{|c|}{$\begin{array}{l}\text { 1. In suspected iron deficiency, serum ferritin is accurate and } \\
\text { precise, dominating other tests, even with inflammatory disease. }\end{array}$} \\
\hline \multirow[t]{7}{*}{ Results } & Size of aneurysm & + LR & $-\mathrm{LR}$ & Ferritin measurement $(\mathrm{ng} / \mathrm{ml})$ & LR \\
\hline & $>3 \mathrm{~cm}$ & 12.0 & 0.72 & $<15$ & 51.85 \\
\hline & $>4 \mathrm{~cm}$ & 15.6 & 0.51 & $>15$ to $<25$ & 8.83 \\
\hline & & & & $>25$ to $<35$ & 2.54 \\
\hline & & & & $>35$ to $<45$ & 1.83 \\
\hline & & & & $>45$ to $<100$ & 0.54 \\
\hline & & & & $>100$ & 0.08 \\
\hline Source & \multicolumn{3}{|c|}{$\begin{array}{l}\text { Systematic review of studies of examination for AAA, } \\
\text { involving } 2955 \text { patients }\end{array}$} & \multicolumn{2}{|c|}{$\begin{array}{l}\text { Systematic review of studies with marrow iron as standard, } \\
\text { involving } 2579 \text { patients }\end{array}$} \\
\hline Citation & \multicolumn{3}{|c|}{ JAMA 1999;281:77-82. } & \multicolumn{2}{|l|}{ J Gen Intern Med 1992;7:145-53. } \\
\hline eCAT date & \multicolumn{3}{|l|}{9 January 1999} & \multicolumn{2}{|l|}{10 August 1998} \\
\hline
\end{tabular}

write our own eCATs, how can we use our PDAs to carry summaries of evidence that others have prepared? Beyond swapping eCATs with our colleagues who share our clinical interests and methodological rigour, there are some software resources we can try, although they vary in how explicitly they use evidence.

In an older woman admitted for an acute febrile illness, the rapid test of a nasal swab confirms our suspicion of influenza A. To help us decide whether to start an antiviral drug, we open a PDA version of Clinical Evidence (table 2), tapping through the menus to the evidence summary that oseltamivir is effective in reducing the duration of illness [13 seconds]. After discussing the potential benefits and harms, we decide to offer oseltamivir treatment to the patient, but first we tap open the ePocrates drug information software (table 2) to obtain the proper dose and to check for drug-drug interactions with her other medications [11 seconds].

A middle aged woman was admitted for her first ever seizure. Our evaluation so far has not found a toxic, metabolic, or structural cause. To help us decide whether to begin antiepileptic treatment, we open Clinical Evidence again, where we learn that drug treatment lowers the recurrence rate of seizures by about half, although the long term benefit is uncertain [12 seconds].

A middle aged man was admitted for an exacerbation of chronic obstructive airway disease. He's quite sick and not yet responding to initial therapy, so we discuss contingency plans, including when he might need intensive care. To inform this discussion, we open the Palm OS summary of the Global Initiative for Chronic Obstructive Lung Disease (GOLD) practice guidelines, focusing on the indications for admission to intensive care [9 seconds].

As we travel between hospital floors, we talk about an article from the most recent issue of the Annals of Internal Medicine that will be reviewed at our departmental journal club the next day. While we wait for another team member to answer a page, one of us taps open JournalToGo (table 2), with which we had already downloaded (at last synchronisation of PDA with computer) the latest abstracts from this and many other journals, and finds the citation's abstract for us to review [11 seconds]. 
Table 2. Some evidence resources for PDAs

\begin{tabular}{lll} 
Resource & Platform & Web site \\
Clinical EvidencePalm & Pocket PC & www.bmj.com/handhelds/ \\
\hline UpToDate & Pocket PC & www.uptodate.com \\
\hline EPocrates & Palm & www.epocrates.com \\
\hline GOLD guidelines & Palm & www.goldcopd.com \\
\hline EBMCalc & Palm & $\begin{array}{l}\text { www.cebm.utoronto.ca/ } \\
\text { palm/ebmcalc/ }\end{array}$ \\
\hline JournalToGo Palm & Pocket PC & www.journaltogo.com \\
\hline
\end{tabular}

A middle aged woman was just found to have stage IV renal cell carcinoma. To prepare ourselves to discuss the future with her, we turn on a Pocket PC-based PDA, open UpToDate (table 2) and find that patients with her stage at diagnosis have a median survival of about 10 months, with an average 5 year survival less than $10 \%$ [75 seconds].

Another middle aged woman was admitted for dyspnea. We suspect heart failure but want to exclude pulmonary embolism. Her $\mathrm{D}$ dimer test result is negative, so we open another eCAT to learn that the sensitivity of the $\mathrm{D}$ dimer test is about $98 \%$ and the specificity is $45 \%$ [ 5 seconds]. We then open the Palm OS-based calculator program EBMCalc (table 2), select "Diagnostic Tests", enter the values and tap "Calculate", yielding not only the respective likelihood ratios and confidence intervals but also a graphical display of how the post-test probability varies with pretest probability and these test results (Figure) [20 seconds, with lots of "Ooohs"].

Alright-what about when there's no relevant evidence stored on our PDAs?

Our last patient is an older man referred for profound weight loss. We suspect major depression is the underlying disorder. One member of the team asks how frequently involuntary weight loss is the main presenting problem in patients with depression. We decide to find evidence about this question later to report back to the group, so we open our To Do list, tap open our list of Educational Prescriptions, and capture the question before it fades from memory [15 seconds]. ${ }^{2}$

As anticipated by others, ${ }^{13}$ these rounds illustrate the tremendous potential of the PDA to enhance evidence-based clinical practice by delivering synopses of evidence to the bedside rapidly enough to actually

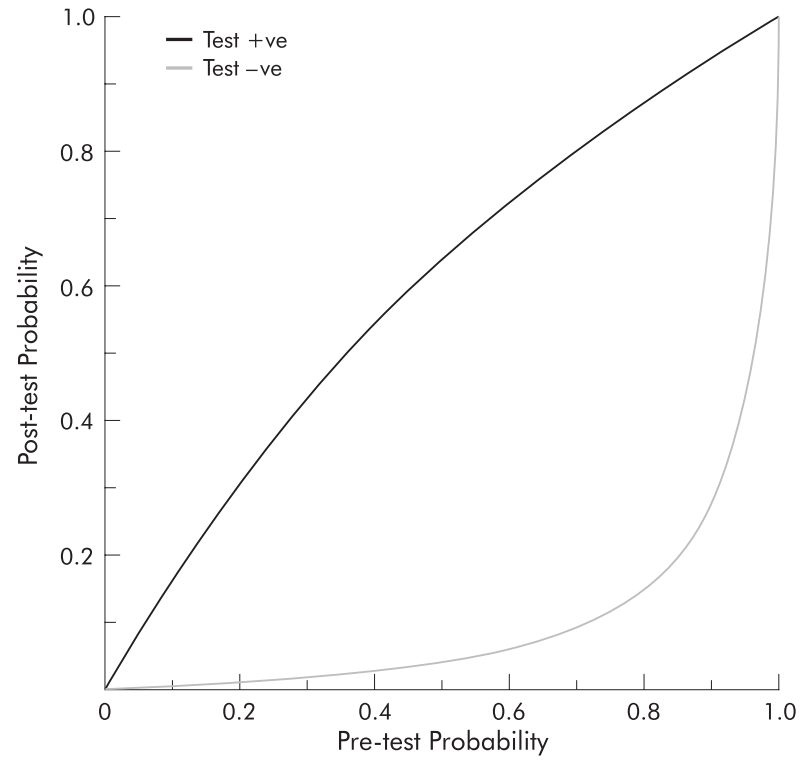

Figure. Graph of post-test probability if sensitivity $=98 \%$ and specificity $=$ $45 \%$, similar to graphic produced by EBMCalc.

inform clinical decisions. As the technology improves further, not only will more resources be able to be stored on PDAs, but wireless access to networks and the world wide web will put even more resources at our fingertips. Because synopses don't tell the full story, we have to be just as careful when applying evidence from our PDA as we would be when using other evidence summaries. At present, no single PDA resource meets all of our evidence needs, so we'll continue to use a combination of our own eCATs and resources made by others.

W SCOTT RICHARDSON, MD STEVEN D BURDETTE, MD Department of Internal Medicine Wright State University School of Medicine Dayton, Ohio, USA 1 Adatia FA, Bedard PL. "Palm reading": 1. Handheld hardware and operat-

ing systems. CMAJ 2002;167:775-80. Sackett DL, Straus SE, Richardson WS, et al. Evidence-based medicine: How
practice and teach EBM. 2d ed. Edinburgh: Churchill Livingstone, 2000. practice and teach EBM. 2 ded. Edinburgh: Churchill Livingstone, 2000.
Helwig AL, Flynn C. Using palm-top computers to improve students' evidence-based decision making. Acad Med 1998;73:603-4.

\section{Journals reviewed for this issue*}

Acta Obstet Gynecol Scand
Age Ageing
Am J Cardiol
Am J Med
Am J Obstet Gynecol
Am J Psychiatry
Am J Public Health
Am J Respir Crit Care Med
Ann Emerg Med
Ann Intern Med
Ann Surg
Arch Dis Child
Arch Gen Psychiatry
Arch Intern Med
Arch Neurol

Arch Pediatr Adolesc Med

Arch Surg

Arthritis Rheum

BJOG

$\mathrm{BMJ}$

Br J Gen Pract

Br J Psychiatry

Br J Surg

CMAJ

Chest

Circulation

Cochrane Library

Crit Care Med

Diabetes Care

Gastroenterology
Gut

Heart

Hypertension

JAMA

J Am Coll Cardiol

J Am Coll Surg

J Am Geriatr Soc

J Clin Epidemiol

J Fam Pract

J Gen Intern Med

J Infect Dis

J Intern Med

J Neurol Neurosurg Psychiatry

J Pediatr
J Vasc Surg

Lancet

Med Care

Med J Aust

$\mathrm{N}$ Engl J Med

Neurology

Obstet Gynecol

Pain

Pediatrics

Rheumatology

Spine

Stroke

Surgery

Thorax

*Approximately 60 additional journals are reviewed. This list is available on request. 
How to cite material from Evidence-Based Medicine

Citation of material from the Notebook

Milne R, Hicks N. Evidence-based purchasing [EBM Note]. Evidence-Based Medicine 1996 May-Jun;1:101-2.

Citation for material taken from a structured abstract, written without attribution by a staff member

Antihypertensive drugs decrease mortality, coronary events, and stroke in elderly persons [abstract]. Evidence-Based Medicine 1996 May-Jun;4:105. Abstract of: Pearce KA, Furberg CD, Rushing J. Does antihypertensive treatment of the elderly prevent cardiovascular events or prolong life? A meta-analysis of hypertension treatment trials. Arch Fam Med 1995;4:943-50.

Citation for material taken from a commentary to an article

Olds D. Commentary on "Home visiting programmes reduce childhood injury." Evidence-Based Medicine 1996 May-Jun;4:112. Comment on: Roberts I, Kramer MS, Suissa S. Does home visiting prevent childhood injury? A systematic review of randomised controlled trials. BMJ 1996;312:29-33.

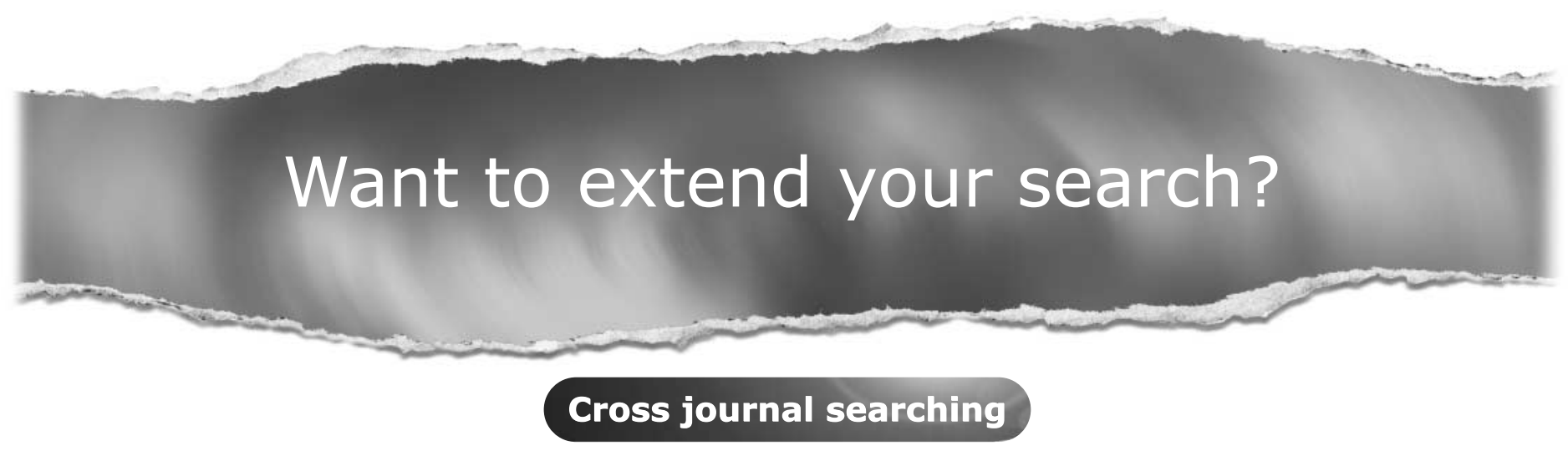

If you can't find what you are looking for in Evidence-Based Medicine you can extend your search across many of the more than 300 journals available for selection. You can restrict your search to specific subject areas (eg, clinical psychiatry, basic research), or select specific journals, or search all available titles.

\section{www.evidence-basedmedicine.com}

